\title{
Comparison of mammography and ultrasonography findings with pathology results in patients with breast cancer in Birjand, Iran
}

\author{
Fatemeh Haghighi ${ }^{1}$, Ghodratollah Naseh ${ }^{2}$, Mahyar Mohammadifard ${ }^{3}$, Naeeme Abdollahi ${ }^{4}$
}

${ }^{1}$ Associate Professor of Pathology, Department of Pathology, Imam Reza Hospital, Birjand University of Medical Sciences, Birjand, Iran

${ }_{2}^{2}$ Assistant Professor of Surgery, Department of Surgery, Imam Reza Hospital, Birjand University of Medical Sciences, Birjand, Iran

${ }^{3}$ Associate Professor of Radiology, Department of Radiology, Imam Reza Hospital, Birjand University of Medical Sciences, Birjand, Iran

${ }^{4}$ Naeeme Abdollahi, Intern, Imam Reza Hospital, Birjand University of Medical Sciences, Birjand, Iran

\section{Type of article: Original}

\begin{abstract}
Background: Early diagnosis of breast cancer, the incidence of which among Iranian women is about a decade earlier than in developed countries, is important.

Objective: To compare mammography and ultrasonography findings with those of pathology in patients with breast cancer.

Methods: This descriptive cross-sectional study was performed using medical records of 79 patients with breast malignancies, who were referred to Imam Reza Hospital and private laboratories of Birjand, Iran, from December 2012 to December 2014. The patients' information was recorded using a checklist, which included name, code, age, ultrasonography, and mammography results and pathology reports. The results of ultrasonography and mammography were compared with pathology findings as the gold standard. SPSS Version 21 was used for data analysis.

Results: The mean age of the patients was $46.94 \pm 11.76$ years. The results showed that $74.7 \%, 16.5 \%$, and $7.6 \%$ of the patients had ductal carcinoma, lobular carcinoma, and mixed carcinoma, respectively. About $72.5 \%$, $24.6 \%$, and $2.9 \%$ of the patients had stage 2,3 , and 1 breast cancer, respectively. In addition, both breasts were involved in $1.3 \%$ of the patients. The ultrasound findings were positive and false negative in $97.5 \%$ and $2.5 \%$ of the cases. Moreover, the mammography results were positive and false negative in $98.7 \%$ and $1.3 \%$ of the patients.

Conclusion: This study showed that mammography is the preferred modality in screening breast cancer patients; the use of complementary tests such as ultrasonography is recommended, especially in high-risk women.

Keywords: Biopsy; Breast cancer; Mammography; Ultrasonography
\end{abstract}

\section{Introduction}

Breast cancer is the most common malignancy and is the second cause of mortality from cancer in the adult female population. It is a hormone-dependent disease, and the age of menarche, first pregnancy, and menopause have a major effect on its incidence (1). The risk of breast cancer is one per eight women, and its lifetime risk is $12.5 \%$ (2). In addition, female-to-male incidence rate ratio of breast cancer is 150/1. The early diagnosis, size of the tumor and its spread, and the lymph node involvement at the time of diagnosis play an important role in choosing the type of surgery and further treatments for these patients (3). Breast cancer in Iranian women occurs about a decade earlier than it does in women from developed countries. In Iran, the prevalence rate of breast cancer is 120 per 100,000

\section{Corresponding author:}

Associate Professor Dr. Mahyar Mohammadifard, Department of Radiology, Imam Reza Hospital, Birjand University of Medical Sciences, Birjand, Iran.

Tel/Fax: +985138414499, Email: Mahyarmohammadifard@yahoo.com

Received: June 14, 2016, Accepted: November 02, 2016, Published: October 2017

iThenticate screening: August 28, 2016, English editing: December 22, 2016, Quality control: September 12, 2017

(c) 2017 The Authors. This is an open access article under the terms of the Creative Commons Attribution-NonCommercialNoDerivs License, which permits use and distribution in any medium, provided the original work is properly cited, the use is non-commercial and no modifications or adaptations are made. 
cases, and its incidence rate is 22 per 100,000 cases. The highest incidence rate of breast cancer is found in 40 - to 49 -year-old women, so that about $23 \%$ of cases of breast cancer in Iran are diagnosed at ages lower than 40 years (4). Also, the mean of tumor size is more than $2 \mathrm{~cm}$ in $72 \%$ of Iranian women, and the lymph node involvement at the time of diagnosis is observed among $63 \%$ of them, which represents the high risk of advanced breast cancer incidence in Iranian women (1). Considering the high risk of advanced breast cancer in Iranian women and the fact that the age range of patients with breast cancer is low (between 40-49), early diagnosis and determination of the exact size of the tumor before surgery are crucial in choosing the appropriate treatment plan (1). Biopsy is the standard and definitive diagnostic method of breast malignancies; however, patients typically avoid this method due to its aggressive nature. Ultrasonography and mammography are two common noninvasive tests for breast examination that are used for screening (mammography) and detection that leads to increased survival rate (5). Screening combined with mammography leads to reduced rate of breast cancer mortality by $22 \%$ in women over 50 years of age, and $15 \%$ in women aged between $49-40$ years. Nonetheless, mammography sensitivity is strongly affected by breast density, and sensitivity of mammography reduces as a result of increasing breast density by $30 \%$ to $48 \%$ (6). Ultrasonography and mammography play an important role in early diagnosis of breast cancer and reducing its mortality rate. Additionally, these modalities are available and affordable for most patients. Sensitivity of ultrasonography and mammography is different in various studies and sources. Therefore, the increasing incidence rate of breast cancer as a major healthcare problem, as well as its early diagnosis and treatment, can significantly affect the clinical course and prognosis. Breast cancer is one of the most common malignancies among Iranian women; however, the epidemiological aspects of breast cancer are not clear among Iranian women (7). Although there are ample studies assessing the frequency of breast cancer in Iran $(4,8)$, none of them has compared the mammography and ultrasonography findings with pathology results in patients with breast cancer in East Iran. This study aimed to compare the mammography and ultrasonography findings with pathology results in patients with breast cancer, who were referred to Imam Raza Hospital and private laboratories of Birjand, Iran, during 20122014.

\section{Material and Methods}

This descriptive, cross-sectional was performed using clinical records of 79 patients with breast malignancies, who were referred to Imam Reza Hospital and private laboratories of Birjand, Iran, from December 2012 to December 2014. The samples were chosen through census sampling. The patients with breast cancer whose ultrasonography, mammography, and biopsy reports were available were entered in this study. Lack of completed and signed consent or one of the required reports (ultrasonography, mammography, and biopsy) was the exclusion criteria. After approval of the experimental design by the University Research Council and Ethics Committee of Birjand University of Medical Sciences, a letter of permission was received from the relevant authorities. Then, the required arrangements in order to refer to the laboratory centers were done to implement the action plans. A checklist containing patient's name, code, age, ultrasonography results (positive, suspected of negative, the presence or absence of calcification, and the number of lymph nodes), mammography results (positive, suspected of negative, the presence or absence of calcification, and the number of lymph nodes), and pathology reports (histopathological type of lesion, the presence or absence of necrosis, calcification, vascular involvement, and the number of lymph nodes) was prepared. The results of ultrasonography and mammography were compared with those of pathology, as the gold standard mean and standard devotion were performed using SPSS Version 21. P-value less than 0.05 was considered significant. The study protocol was approved by the Ethics Committee of Birjand University of Medical Sciences. The obtained data were only used for research purposes, and all the principles of confidentiality were respected.

\section{Results}

The results showed that $32.5 \%, 45.5 \%$, and $32.1 \%$ of the patients were younger than 40 , between 41 and 60 , and above 61 years of age, respectively. The mean age of the patients was $46.94 \pm 11.76$ years, and their age range was between 26 and 85 years. Additionally, $74.7 \%, 16.5 \%$, and $7.6 \%$ of the patients had ductal, lobular, and mixed carcinomas, respectively. It was found that $1.3 \%$ of the patients had infiltrating ductal carcinoma, and three cases had invasive mucinous. Moreover, $72.5 \%, 24.6 \%$, and 2.9\% of the cases were stage 2, 3, and 1 of breast cancer, respectively. The results indicated that the right breast was involved in $44.9 \%$ of the patients, while the left breast was involved in $53.8 \%$ of the cases. In addition, both breasts were involved in $1.3 \%$ of the patients. The results demonstrated that the central area was involved in $16.5 \%$ of the patients. The internal upper, upper external, lower internal, and lower external of breast were involved in $16.5 \%, 2.5 \%, 73.4 \%, 5.1 \%$, and $2.5 \%$ of the patients, respectively. The ultrasonography, mammography, and biopsy findings are shown in Table 1. According to Table 1, the results of ultrasonography in $97.5 \%$ and $2.5 \%$ of the patients were positive and false negative, respectively. Also, 
the mammography results were positive and false negative in $98.7 \%$ and $1.3 \%$ of the cases, respectively. The mean number of nodes involved in the pathologic assessment was $1.32 \pm 2.79$, and the number of involved nodes ranged between 0 and 12. This value was $1.02 \pm 2.04$ in ultrasonography, which ranged between 0 and 10 nodes. In addition, the mean number of nodes was $0.83 \pm 2.02$ in mammography and ranged between 0 and 10 nodes.

Table 1. Obtained results of ultrasonography, mammography, and biopsy

\begin{tabular}{|c|c|c|c|c|}
\hline \multicolumn{3}{|c|}{ Diagnostic methods } & $\mathrm{n}$ & $\%$ \\
\hline \multirow[t]{7}{*}{ Mammography } & \multirow[t]{3}{*}{ Result } & Benign & 1 & 1.3 \\
\hline & & Malignant & 34 & 43 \\
\hline & & Suspicious & 42 & 53.2 \\
\hline & \multirow[t]{2}{*}{ Calcification } & Positive & 3 & 3.8 \\
\hline & & Negative & 76 & 96.2 \\
\hline & \multirow[t]{2}{*}{ Lymphadenopathy } & Positive & 20 & 25.3 \\
\hline & & Negative & 59 & 74.7 \\
\hline \multirow[t]{7}{*}{ Ultrasonography } & \multirow[t]{3}{*}{ Result } & Benign & 2 & 2.5 \\
\hline & & Malignant & 21 & 26.6 \\
\hline & & Suspicious & 56 & 70.9 \\
\hline & \multirow[t]{2}{*}{ Calcification } & Positive & 9 & 11.4 \\
\hline & & Negative & 70 & 88.6 \\
\hline & \multirow[t]{2}{*}{ Lymphadenopathy } & Positive & 25 & 31.6 \\
\hline & & Negative & 53 & 67.1 \\
\hline \multirow[t]{8}{*}{ Biopsy } & \multirow[t]{2}{*}{ Necrosis } & Positive & 20 & 25.6 \\
\hline & & Negative & 58 & 74.4 \\
\hline & \multirow[t]{2}{*}{ Vascular involvement } & Positive & 63 & 79.8 \\
\hline & & Negative & 16 & 20.3 \\
\hline & \multirow[t]{2}{*}{ Calcification } & Positive & 17 & 21.5 \\
\hline & & Negative & 62 & 78.5 \\
\hline & \multirow[t]{2}{*}{ Lymphadenopathy } & Positive & 23 & 29.1 \\
\hline & & Negative & 56 & 70.9 \\
\hline
\end{tabular}

\section{Discussion}

The results of the present study showed that the majority of the patients were in the 40- to 49-year-old age group. Similar to our study, the age range of patients with breast cancer was between 40 and 49 years (mean: 47 years) in a study by Harirchi et al. (4). This result is in agreement with other studies conducted in Iran (7, 9-11). In our study, ductal carcinoma, lobular cancer, and complex cancer were the most common types of breast cancer, respectively. Quite in line with our study, ductal carcinoma was found to be the most common type of breast cancer in other studies carried out in Iran and other countries $(7,9)$. The majority of our patients had stage 2 breast cancer. In accordance with our study, Harirchi et al. reported that about $96 \%$ of the patients had stage 2 breast cancer (9). According to our study, mammography and ultrasonography results were positive in the majority of breast cancer patients, and these results were false negative in a small percentage of them. Similar to our study, the obtained results of Farokh et al. showed that ultrasonography was a certain diagnostic test for detecting breast cancer in patients with high density breasts (stage 3 and 4), and mammography was more accurate than ultrasonography in determination of the size of tumor before surgery (12). The sensitivity and specificity of ultrasonography was compared with mammography findings and clinical examination in a study by Shafiee et al. According to that study, the sensitivity and specificity of ultrasonography were higher than mammography examination $(25.8 \%$ and $71.9 \%$ vs. 5\% and 7.1\%). Therefore, mammography was not a reliable diagnostic test in diagnosis of breast cancer (13). In a study by Gharekhanloo et al., the mammography results were negative in $14.3 \%$ of patients because of high density of the breast. For this reason, mammography is the preferred modality in screening breast cancer. Considering the incidence of breast cancer at a comparatively young age and dense breast in these ages, ultrasonography is recommended as an additional test in patients of a lower age group to increase diagnostic sensitivity (14). In our study, the sensitivity and specificity of mammography were calculated to be $73 \%$ and $55 \%$, and the rate of false negative was $17.27 \%$. In a study by Haghighatkhah et al., the sensitivity and specificity of ultrasonography were $99 \%$ and $70 \%$, respectively, and the rate of false negative was $17.68 \%$. In addition, that study showed a significant difference between the sensitivity of ultrasonography in diagnosis of breast cancer and age and previous history of breastfeeding and pregnancy. Therefore, the most important factors influencing the sensitivity of 
ultrasonography in the diagnosis of breast cancer are age, previous history of breastfeeding, and pregnancy (5). The sensitivity and specificity of color Doppler sonography and power Doppler in differentiating benign and malignant lesions were assessed in a study by Ahmadinezhad and colleagues. The results showed that the sensitivity and specificity of ultrasonography in the diagnosis of malignant tumors were $73 \%$ and $82 \%$, respectively. In that study, sensitivity of ultrasonography was lower than that of mammography. Therefore, ultrasonography cannot be employed as a full screening test and can be applied as a complementary test to differentiate benign and malignant lesions and to avoid unnecessary biopsies (15). The results of studies conducted in Iran were similar to those of other countries. The sensitivity of mammography and ultrasonography in the diagnosis of nonpalpable cancers was evaluated by Leconte et al. The findings indicated that the sensitivity of mammography and ultrasonography were $69 \%$ and $88 \%$ in stage $1-4,80 \%$ and $88 \%$ in stages 1 and 2 , and $56 \%$ and $88 \%$ in stages 3 and 4 , respectively. Mammography is more effective in diagnosis of nonpalpable cancers in stage 1-4 than ultrasonography but not in stages 1 and 2 (16). Sickles et al. study demonstrated that ultrasonography is not an acceptable substitute for mammography in diagnosis of breast cancer (17). A study reviewing all the studies performed from 1999 to 2009 showed that magnetic resonance imaging is more effective than ultrasonography, mammography, and clinical examination in diagnosis of residual tumors after chemotherapy and accurate assessment of the extent of carcinoma (18). Another advantage of magnetic resonance imaging is its lower costs, as compared with those for mammography and ultrasonography (19). However, it cannot substitute mammography due to its low specificity (18). The possible caused by biopsy and other complementary tests in women without breast cancer is one of the main concerns about screening. According to a study by Berg et al., the majority of screen-detected invasive breast cancers were node-negative, and the risk of false positives decreased significantly by sonographic screening along with mammography and magnetic resonance imaging (20).

\section{Limitations and Recommendations}

This retrospective study was performed by gathering data from medical records of patients; thus, careful examination of the patients in terms of pregnancy, lactation, or the use of hormonal pills during imaging or pathological sampling was not possible. Therefore, performing further prospective studies evaluating the main factors affecting breast tissue such as pregnancy and hormonal drugs, as well as determining the treatment methods and the rate of patients responding to the treatment, is recommended to provide more information about the disease.

\section{Conclusions}

This study showed that mammography is the preferred modality in screening breast cancer patients. Given that the sample population used in this study was aged less than 35 , the use of complementary tests such as magnetic resonance imaging and ultrasonography is suggested for diagnosis of malignant and benign lesions in cases with high breast density, increasing the speed of detection, and also reducing the costs, especially in high-risk women.

\section{Acknowledgments:}

This study was derived from a master's thesis performed during 2012-2014. We wish to thank the staff of Imam Raza Hospital and private laboratories of Birjand for their cooperation with this study.

\section{Conflict of Interest:}

There is no conflict of interest to be declared.

\section{Authors' contributions:}

All authors contributed to this project and article equally. All authors read and approved the final manuscript.

\section{References:}

1) Chabner B, Longo D. Harrisons Manual of Oncology 2/E. McGraw-Hill Education; 2013.

2) Rockall AG, Hatrick A, Armstrong P, Wastie M. Diagnostic Imaging: Wiley E-Text. 7th Edition; 2013.

3) Brunicardi FC, Brunicardi F, Andersen D, Billiar T, Dunn D, Pollock RE, et al. Schwartz's Principles of Surgery. 9th Edition. McGraw-Hill Education; 2009.

4) Harirchi I, Karbakhsh M, Kashefi A, Momtahen AJ. Breast cancer in Iran: results of a multi-center study. Asian Pac J Cancer Prev. 2004; 5(1): 24-7. PMID: 15075000.

5) Haghighatkhah H, Shafii M, Khayamzade M, Molaii H, Akbari M. Determination of compliance with mammography or ultrasound reports of pathology reports malignant and benign disease breast. Quart Iran Breast Dis. 2009; 2: 27-32. 
6) Berg WA, Blume JD, Cormack JB, Mendelson EB, Lehrer D, Böhm-Vélez M, et al. Combined screening with ultrasound and mammography vs mammography alone in women at elevated risk of breast cancer. JAMA. 2008; 299(18): 2151-63. doi: 10.1001/jama.299.18.2151. PMID: 18477782, PMCID: PMC2718688.

7) Harirchi I, Ebrahimi M, Zamani N, Jarvandi S, Montazeri A. Breast cancer in Iran: a review of 903 case records. Public Health. 2000; 114(2): 143-5. doi: 10.1038/sj.ph.1900623. PMID: 10800155.

8) Sadjadi A, Nouraie M, Mohagheghi MA, Mousavi-Jarrahi A, Malekezadeh R, Parkin DM. Cancer occurrence in Iran in 2002, an international perspective. Asian Pac J Cancer Prev. 2005; 6(3): 359-63. PMID: 16236000 .

9) Mousavi SM, Montazeri A, Mohagheghi MA, Jarrahi AM, Harirchi I, Najafi M, et al. Breast cancer in Iran: an epidemiological review. Breast J. 2007; 13(4): 383-91. doi: 10.1111/j.1524-4741.2007.00446.x. PMID: 17593043.

10) Parkin DM, Bray F, Ferlay J, Pisani P. Global cancer statistics, 2002. CA Cancer J Clin. 2005; 55(2): 74 108. doi: 10.3322/canjclin.55.2.74. PMID: 15761078 .

11) DeSantis C, Ma J, Bryan L, Jemal A. Breast cancer statistics, 2013. CA Cancer J Clin. 2014; 64(1): 52-62. doi: 10.3322/caac. 21203 .

12) Assi HA, Khoury KE, Dbouk H, Khalil LE, Mouhieddine TH, El Saghir NS. Epidemiology and prognosis of breast cancer in young women. J Thorac Dis. 2013; 5(Suppl 1): S2-8. doi: 10.3978/j.issn.20721439.2013.05.24. PMID: 23819024, PMCID: PMC3695538.

13) Farokh D, Azarian A, Homaii F, Yaghubi N, Khaje deloii M. Compliance review findings of mammography, ultrasound and Histopathology in women with breast cancer less than 50 years. Med J Mashhad Univ Med Sci. 2012; 2(4): 195-200.

14) Shafiee SAB, Rafii M, Kalantari M. Evaluation of the results matched the findings of clinical examination and mammography in detecting breast cancer. Iran J Surg. 2007; 15: 3.

15) Ghare khanloo F, Tarabian S, Kamrani S. The study of the role of Additional ultrasound in diagnosis of breast cancer. J Hamadan Univ Med Sci Health Serv. 2010; 4(5): 60-7.

16) Ahmadinezhad N, Shahriarian S, Ghasemi A, Giti M. Sensitivity and specificity of color Doppler sonography and power Doppler sonography in differentiating benign and malignant breast. J Tehran Univ Med Sci. 1980; 4: 277-82.

17) Leconte I, Feger C, Galant C, Berlière M, Berg BV, D'Hoore W, et al. Mammography and subsequent whole-breast sonography of nonpalpable breast cancers: the importance of radiologic breast density. AJR Am J Roentgenol. 2003; 180(6): 1675-9. doi: 10.2214/ajr.180.6.1801675.

18) Sickles EA, Filly RA, Callen PW. Breast cancer detection with sonography and mammography: comparison using state-of-the-art equipment. AJR Am J Roentgenol. 1983; 140(5): 843-5. doi: 10.2214/ajr.140.5.843. PMID: 6601422.

19) Peyman A, Abbasi Z, Shishegar F. the Comparison between MRI and mammography to diagnosis of breast masses. The First International Congress on Midwifery and Reproductive Health; Iran, Mashhad; 2011.

20) Berg WA, Blume JD, Adams AM, Jong RA, Barr RG, Lehrer DE, et al. Reasons women at elevated risk of breast cancer refuse breast MR imaging screening: ACRIN 6666. Radiology. 2010; 254(1): 79-87. doi: 10.1148/radiol.2541090953. PMID: 20032143, PMCID: PMC2811274.

21) Berg WA, Zhang Z, Lehrer D, Jong RA, Pisano ED, Barr RG, et al. Detection of breast cancer with addition of annual screening ultrasound or a single screening MRI to mammography in women with elevated breast cancer risk. JAMA. 2012; 307(13): 1394-404. doi: 10.1001/jama.2012.388. PMID: 22474203, PMCID: PMC3891886. 